\title{
EL ESTADO Y LA DISCRIMINACIÓN DE GÉNERO. Un estudio empírico: "Rosa dos Ventos”.
}

\author{
Esmeralda Broullón Acuña \\ Universidad de Cádiz
}

\section{RESUMEN:}

El artículo que presentamos es una aproximación del resultado obtenido en un campo de estudio ubicado en una sociedad marítimo-pesquera. En concreto versa sobre la trayectoria de un movimiento social femenino formado en los años noventa en la Ría de Vigo (Pontevedra), erigiéndose como "la voz de los sin voz", denominado "Rosa de los Vientos". El grupo nace con la intención de promover un cambio social para los hombres que trabajan en el mar, así pues los principales destinatarios de sus acciones son los marineros de los barcos de altura, quienes carecen de posibilidades para la reivindicación de mejoras en las condiciones de vida en tierra y en alta mar. Traemos a colación el resultado de su irrupción en el espacio público, de ahí la utilización de fuentes orales, concluyendo el relato con su inclusión finalmente en el orden gubernamental, y el regreso al reducto privado femenino.

Palabras Clave: Políticas estatales, sociedades marítimo-pesqueras, mecanismos de control, orden social legitimado, asociacionismo femenino, derechos humanos,

\section{ABSTRACT:}

The article that we introduce is an approximation of the obtained results in a field of study located in a maritime fishing society. Exactly, it speaks of a female population trajectory, formed as a collective in the nineties in Vigo (Spain). The group is born with the intention to promote a social change for the men that work in the sea, thus therefore the main recipients of their actions are the height and great height fishermen. We bring to collation the own decision making, with an impulse from the confined private space to public space, for this cause, the central utilization of oral sources. We will conclude the relation of this association ("Rose of the Winds") with a reference to the final inclusion in the governmental order, and the subtle return to the female private redoubt.

Key Words: State politics, marine-fisheries societies, forms of control, legitimized social order, female association. 


\section{EL ESTADO Y LA DISCRIMINACIÓN DE GÉNERO. Un estudio empírico: "Rosa dos Ventos”.}

La vida de los seres humanos en las sociedades está reglamentada mediante políticas estatales que influyen en éstos de manera decisiva, y de forma especial intervienen en las mujeres por la posición ocupada en la estructura social. Dichas reglamentaciones regulan exigencias y modos de ser de la población. En el seno de nuestra cultura occidental estas representaciones refieren a unas formas de control que se ejercen particularmente sobre sectores de población, al implementar ordenaciones, leyes penalizadoras y normalizadoras, entre otras, sobre el matrimonio y el divorcio, como también determinados modos de cohabitación que orientan hacia una determinada organización familiar. Se trata de fomentar delimitados comportamientos en el seno de las relaciones sociales, que llegan a ser institucionalizados, bajo un criterio de idoneidad y heterodesignación. Igual ocurre con determinadas normativas y programas de control demográfico, que en nuestra sociedad sustenta en definitiva una división sexual del trabajo dentro de la familia, tal como se manifiesta a lo largo de la historia. De esta manera, podemos advertir la trayectoria recorrida por los sujetos, bajo un despliegue de disposiciones, en la estructura ocupacional segregacionista de la población, donde observamos una jerarquización de profesiones, incluida la representación de las mujeres como "ejército de reservas" y la construcción de un "salario familiar", haberes flexibles, tras unos mecanismos articuladores de la vida en sociedad.

Mediante el análisis de los discursos mostrados, pretendemos exponer las argumentaciones contenidas en las prácticas y creencias de los sujetos sociales y las ideologías del género que perfilan conceptos de masculinidad/feminidad, perpetuados por los aparatos ideológicos estatales ${ }^{2}$ como la escuela o la familia, a modo de mecanismo amortiguador de las contradicciones de la lógica del capitalismo avanzado, convirtiéndose la familia en institución sustituta del Estado de Bienestar. Cuando las políticas estatales hablan de la familia encubren el peso que recae en las mujeres ${ }^{3}$, pese a lo manifestado por los partidos políticos y sindicatos, con programas o discursos aperturistas y progresistas. Las políticas sociales no incluyen ni afectan por igual a toda la población, y ello es más evidente en el caso del desmantelamiento del Estado del Bienestar. Desde un punto de vista empírico, teniendo en cuenta consideraciones de sexo, clase y etnia, comprobamos, al hilo de los fragmentos relatados, las modificaciones dadas en las relaciones entre el Estado y las mujeres, aproximándonos a una concreta ideología del poder que con determinados mecanismos institucionaliza ciertas prácticas y proceder femeninos. Al respecto, señalamos la trayectoria de una organización femenina sobre la cual versa nuestro artículo:

"Desde el momento que creamos la asociación que nació para luchar por unos derechos de los hombres, porque es que ellos estaban en el mar y ellos no piden..., bien, la asociación fue bien. También estupendo los encuentros con otras asociaciones: mujeres vascas, con las francesas y así, porque nosotros es que estamos con respecto a las francesas a años luz. Pero claro a medida que nos fuimos consolidando, haciendo otras cosas, como cursos, talleres y todas esas 'trapalladas', ¡que sí que para mí son bonitas! pintar telas, hacer un taller de cocina, cursillos de autoestima, -cuidado que yo me tengo mucha autoestima- relajación... Pero si te paras un poco a pensar, ahora recibimos dinero por nuestra asociación y ¿qué?, ¿ahora qué? calladitas y modositas

\footnotetext{
${ }^{1}$ Véase BORDERÍAS, C. y LÓPEZ GUALLAR, P.: "La teoría del salario obrero y la subestimación del trabajo femenino", en Idelfonso Cerdà, Quaderns del Seminari d'historia de Barcelona, 5, Barcelona, 2001.

${ }^{2}$ Véase ALTHUSSER, L., Ideologías y aparatos ideológicos del Estado, Nueva Visión, Buenos Aires, 1974 (1970).

${ }^{3}$ El desmantelamiento del Estado de Bienestar precisa la revitalización de los valores de la familia patriarcal. Véase R.Z. EISENTEIN, <The sexual politics of the New Right.understanding the "Crisis of Liberalism for the 1980s">, en M ROSALDO y B. GELPI, Feminist theory. A critique of ideology, Chicago, University of Chicago Press, 1982.
} 
para cuando tengamos que poner unos puntos e ir a Bruselas. Mira está claro que hay una diferencia...".

Durante el tiempo transcurrido en el terreno de campo, donde observábamos el alcance de las políticas de Estado sobre la población femenina, constatamos como algunas mujeres en las sociedades halieuticas pasaron a la "acción" de lo público 5 , a la reivindicación social, al ser fieles conocedoras de la vida en el mar y la peligrosidad del trabajo de los hombres, siendo ellas y su entorno los directos implicados por la falta de dignidad humana que conlleva la citada actividad laboral ${ }^{6}$. Con el tiempo requerido, para cierta toma de confianza, pudimos acceder a su comunidad, a su asociación, que en un principio era de carácter local, luego pasó a ser regional, para más tarde ser absorbidas por una politeia mayor: la de la Unión Europea.

"Rosa dos Ventos" es su nombre, símbolo en la orientación de los puntos cardinales. Tras conocer el activismo de su movimiento social, entendimos que el camino trazado en su historia de vida se hizo "andando", y en ese tránsito se impuso la elección, que como tal, consistió en abandonar otros caminos posibles. La colectividad que la constituye, a través de sus actos y apuesta de futuro representan un ejemplo significativo de trasgresión de los espacios habitados por las mujeres, ya que éstas no han sido por lo regular sujetos del conocimiento; sí en cambio persistentes objetos en la histórica división del trabajo, en base al género. Pero mediante sus acciones conocimos la verdadera naturaleza de la relación entre el Estado y el género.
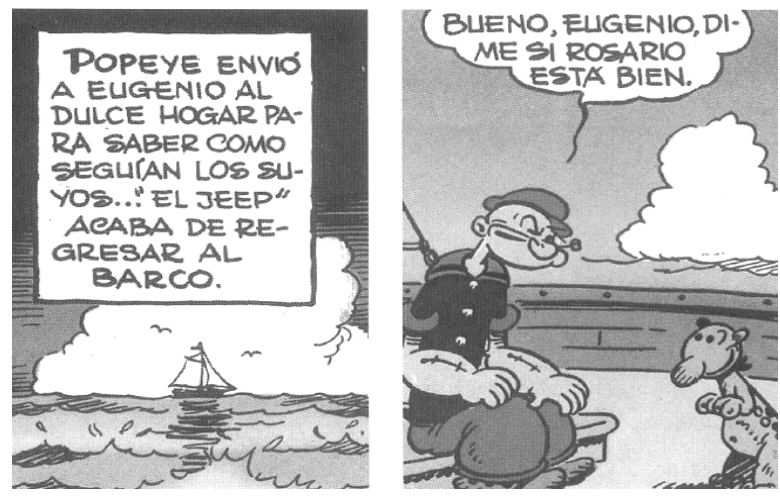

Fuente: Boga.

Revista Internacional de Mujeres de Pescadores, $\mathrm{n}^{\circ}$ 8, 2000.

"Rosa dos Ventos" habla de la trayectoria de unas mujeres de pescadores de las Rías Bajas en el ámbito del asociacionismo, primero con carácter comunitario y espontáneo hasta su formalización con un centenar de socias en febrero de 1991. El trasfondo de su discurso estaba centrado en la reivindicación de un futuro más digno y mejor para las familias marineras. La conexión entre los distintos grupúsculos de los movimientos sociales femeninos, hunde sus raíces a mediados de los años ochenta, promovida por el "Apostolado del mar" a través de las parroquias marítimas. Aunque dichos grupos estaban más centrados en la reflexión, pronto inician contactos entre sí y comienzan su andadura con un trabajo encaminado en la defensa del respeto a la

\footnotetext{
${ }^{4}$ Mujer, 42 años. Ex miembro de la asociación "Rosa dos Ventos". Cangas, Pontevedra. Septiembre del 2004

${ }^{5}$ Véase ARDERNER, S.: (ed.), Women and Space: Ground Rules and Social Maps, St. Martin Press, Croom Helm, New York, 1981

${ }^{6}$ Los fundamentos que sostienen las acciones de "Rosa dos Ventos" contienen principios propios de los movimientos ecofeministas del siglo XX. Véase MELLOR, M.: Feminismo y ecología, Siglo XXI, México, 2000 (1997); PULEO, A.: "Feminismo y ecología", en Feminismo. es...y será, Jornadas Feministas, Córdoba, Servicio de Publicaciones Universidad de Córdoba, pp. 227-234, 2001.
} 
dignidad de los trabajadores del mar, reclamando derechos básicos, laborales, familiares y sociales. Otros colectivos van surgiendo en toda la década de los ochenta, entre ellos el de Cangas de Morrazo (Pontevedra), cuya trayectoria pudimos conocer en calidad de observadora participante. En el caso concreto de Cangas, las mujeres se organizan para solidarizarse y apoyar a los maridos, con motivo del conflicto creado en el caladero canario-sahariano, tratando de negociar un convenio colectivo. La labor que llevaron a cabo fue descrita en los siguientes términos:

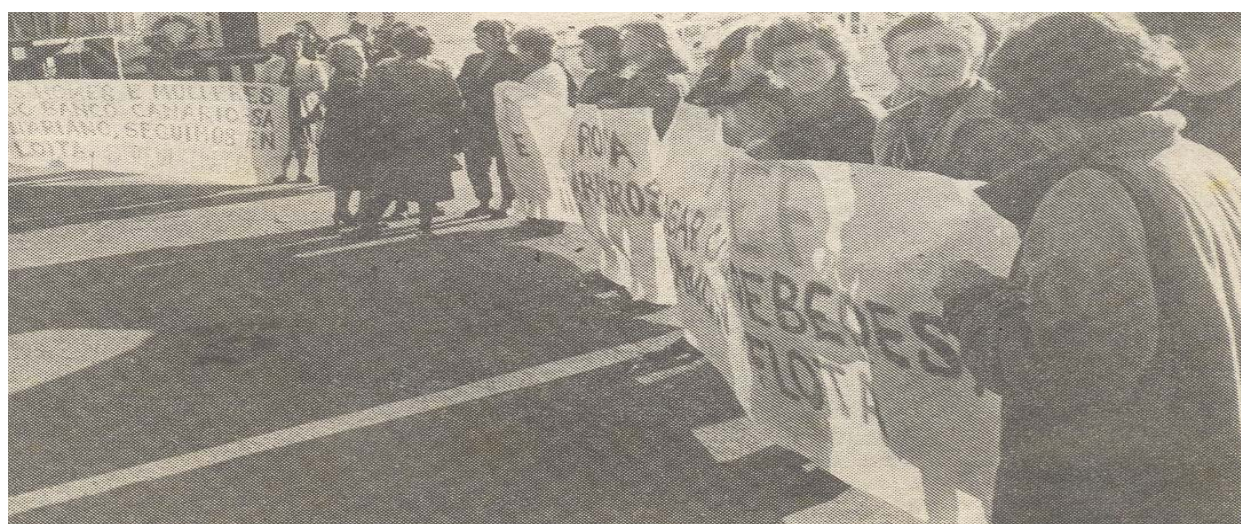

Fuente: Faro de Vigo, 20 de Marzo de 1990.

Mujer 1a: "En el ochenta y ocho empezamos con el problema del banco canario-sahariano. Luchar por un convenio colectivo, luchar precisamente porque hubiera un fraude. Las promotoras de aquello fuimos... y yo, porque si no, non se montaba nada. Fue cuando aún negociaba España los acuerdos pesqueros con Marruecos. Entonces estuvieron cuatro meses negociando el acuerdo y en esos cuatro meses esa gente no ganaba nada, les dieron una ayuda de cincuenta y tres mil pesetas, en el ochenta y ocho. En diciembre paró la flota y se incorporaron después de firmar el acuerdo, después de España regalarle a Marruecos cuatro lanchas, para luego perseguir a los pescadores, arreglarle el muelle de Agadir y hacerles unas cámaras frigoríficas allí. En abril se marcharon otra vez la flota a faenar y fue cuando vino el paro, jera la primera vez que iban a cobrar el paro! Porque otra cosa, los marineros no estaban considerados, no estaban dentro del Estatuto del Trabajador y cuando tenían derecho a cobrar el desempleo los obreros de tierra, los marineros no, y a partir de ese año fue así, porque los marineros eran considerados ciudadanos de segunda categoría (...) A mí me llegara la carta que fuera a cobrar catorce mil pesetas, ¿catorce mil pesetas? Entonces, ¿cuánto cotizan por mi marido?, piensas tú, jesto es un fraude...! A ella le pasaba lo mismo, otra tres mil, otra dos mil..., vamos al sindicato ella y yo y le decimos al sindicalista, $¿$ a ti te parece normal que me paguen de desempleo, de cuatro meses a mi marido, catorce mil pesetas?, ¿qué pasa aquí? Y cuando llamaron los maridos: ¡qué!, ¿cobrasteis el paro? Sí, catorce mil pesetas, otra tres mil, otra seis mil, otra doce, pero ¿esto qué es? Entonces fue cuando ellos empezaron a comunicarse unos con otros y dijeron: ;flota para puerto!, se negaron a trabajar. ¡Vamos a luchar por un convenio! ¡Que nos regulen esto! Y ellos no tenían nada, nada y se empezó a luchar por ese Convenio que al final pues no sé..., toda la lucha que hubo ahí y al final se quedó ¿con qué? Le repercutía a cada marinero, al final de cada año, le repercutía sobre unas ciento, ciento cuarenta y dos mil pesetas que venían a más, que antes nada. Por lo menos ya le ponían de descanso, pagas extras y de vacaciones otro tanto. Entonces, pues ya decías: antes esto no lo tenía y ahora lo tengo, ¿no? Aparte de que hubiera que poner también un sueldo 
garantizado, aunque fuera pequeño, porque ellos iban, pero si el barco no pescaba no ganaban nada, entonces si el barco pescaba..."

Hombre: "Bueno yo no sé ese convenio, fue bastante bueno vale y que sería tal... ipero el resto de los convenios fueron fatales! Os restos dos convenios todos perdimos dinero, los marineros en casi todos os convenios perdemos".

Mujer 2a: "En el de Canarias sí, porque antes no te pagaban ni vacaciones, ni descansos ni nada. Te ponían gratificaciones en donde el armador te las daba, si quería; en donde que después hubo que poner vacaciones, pagas extras, descaso y todo eso algo te aumentó, no es que fuera mucho pero mejoró".

Hombre: "O de Canarias lo que fue rentable en las cotizaciones, pero ganar no".

Mujer 1": "Y después el caballo de batalla eran las cotizaciones, porque cómo puedo cobrar yo de desempleo catorce mil pesetas, ¿cuánto cotizas por mí? Se descubrió ahí un fraude. Entonces, después, había que cotizar, le permitían hacer una complementaria (...). Luego a los sesenta días que venía el barco, según el capital que hicieras y lo que ganaba un marinero, había que cotizar a salario real ¿no? Entonces fue lo que más..., porque sino estos hombres se jubilaban con pensiones míseras de cuarenta y tantas mil pesetas, los de bajura o los que venían del banco canario-sahariano, igual, una miseria, porque cotizaban como si fueran barcos al fresco. Tú sabes aquel día delante de la cooperativa de armadores de Vigo que me preguntaba un periodista, ¿pero cómo pueden ser las cotizaciones? Hombre porque cotizan por barcos al fresco. ¿Ustedes entienden que puede un barco estar 60 días en alta mar, traer el pescado fresco? No, no, porque eran congeladores".

Hombre: "Lo que pasa es que el banco canario-sahariano estaba muy mal regulado, muy mal regulado. El del Gran Sol también... porque la ruina dos marineros do Gran Sol fue o convenio, porque ahora ganan menos que antes y trabajan o doble".

Mujer 2a: "De todas maneras en los barcos, sobre todos en el banco Canario-Sahariano, tú ibas a un porcentaje. Ibas a trabajar y hablabas qué tipo de porcentaje te ponían para ganar y en el mismo barco se dieron casos de distintos porcentajes, siendo igual marinero, no hablamos de titulados porque ya es distinto, pero lo que es la marinería había barcos que ellos iban a un 1,20 y había gente al $0,9 \%$, marineros de primera y de segunda". ${ }^{7}$

Las reivindicaciones de las familias de marineros de este banco pesquero se entienden mejor si antes hablamos de las consecuencias originadas por el congelado en los buques pesqueros, ya que esto llevó aparejado una regresión en las condiciones de trabajo y vida familiar de la tripulación. Los buques-factorías se proyectaron como una extenuación del "fordismo", pues en ellos se exigen mayores conocimientos técnicos, rapidez, precisión y destreza en las faenas a bordo, así como en la manipulación del recurso que a diferencia de los procesos de trabajo anteriores debe ser clasificarse y empacarse. Los hombres se exponen a riesgos de emanaciones de los elementos que surten a las instalaciones frigoríficas, e igualmente dentro de las bodegas de congelación realizan el trabajo a bajas temperaturas, entre $25^{\circ} \mathrm{C}$ y $30^{\circ} \mathrm{C}$ bajo cero. De este modo, las campañas se alargan al disponer de mayor autonomía y mejor mantenimiento del pescado.

La era del congelado en alta mar se inicia a mediados de los años setenta y existen, a pesar de la escasa concienciación social de la marinería, antecedentes en la reivindicación de las mejoras de las condiciones laborales por parte de barcos congeladores, especialmente de Huelva, alcanzado en un nuevo reglamento: "Ordenanza de trabajo en buques congeladores", Orden Ministerial de 19 de diciembre de 1974, en vigor el 1 de enero de 1975, quedando entonces excluidos los barcos congeladores de cefalópodos del banco canario sahariano, que tal como exponen las informantes no percibían un salario fijo mensual, sino que por el contrario su sistema salarial era "a la parte", y por consiguiente se regirían por la Orden Ministerial de 31 de julio de 1976, recogidos en una "Ordenanza de Trabajo para buques arrastreros al fresco", a pesar de la

\footnotetext{
${ }^{7}$ Grupo de debate, mixto. Cangas, Pontevedra. Diciembre del 2005.
} 
contradicción de que algunos de sus tripulantes trabajasen en modernos barcos congeladores, entre cinco y siete meses de trabajo.

Este ha sido, grosso modo la trayectoria socio-laboral de los tripulantes aludidos, de ahí las referencias sobre el estado de las cotizaciones y las retribuciones obtenidas por los esposos, quienes faenando durante largo tiempo en el mar cotizaban como si navegasen "al fresco", es decir, en buques pequeños o de características adscritas al sector "artesanal". Tal contradicción, con efectos perniciosos en sus derechos laborales, daría lugar a una "toma de conciencia" para demandar un convenio colectivo en el que se aplicara un sistema salarial más justo, a base de un "salario fijo inicial". Esto ocurrió más tarde a las Ordenanzas iniciales descritas, cuando la flota de buques congeladores, del cefalópodo, fue aumentando y su numerosa tripulación trabajaba cada vez más en precario, entonces la mayoría eran ya barcos gallegos, del Morrazo. Y es aquí donde situamos la acción de las mujeres gallegas que hemos traído a colación. Después de largas negociaciones, iniciadas el 13 de septiembre de 1988 y finalizadas el 30 de marzo de 1989, se firma un nuevo convenio colectivo de la flota, con un salario base y la participación en las capturas, más la seguridad del salario garantizado. Más tarde, el día 24 de febrero de 1990 entra en vigor un nuevo Real Decreto sobre cotizaciones a la Seguridad Social para la pesca "a la parte". Tal como sostienen las informantes, al menos el convenio fue revisado, si bien es conocido el final de los tripulantes que navegaron en dicho caladero pero esto supone excedernos finalmente de esta exposición.

A la vez, revisamos el tratamiento de sus acciones en la arena pública por diversas fuentes periodísticas, mostrando esta primera crisis de marineros y pescadores, de diferentas comunidades, que faenaban en el banco canario-sahariano, así como el apoyo del colectivo a otros grupos de distinta área peninsular, por las dificultades de las faenas en dichas aguas. Al respecto hemos recopilado noticias como las que siguen:

Fuente: Atlántico, 8 de marzo de 1990.

Mujeres de marineros se manifestarán hoy en Vigo.

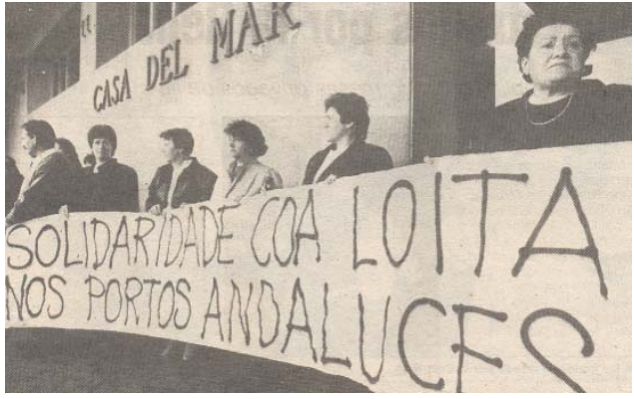

"Las mujeres de los marineros gallegos que faenan en aguas del banco Canario-Sahariano se solidarizaron con los marineros andaluces y gallegos que mantienen bloqueados varios puertos andaluces (...). Las esposas de los marineros anunciaron que se manifestarán en Vigo para protestar por los saqueos, multas y apresamientos de que son objeto los barcos españoles en aguas marroquíes (...) Dos autocares de pescadores gallegos viajarán a Algeciras para sumarse al bloqueo de dicho puerto así como de los de Huelva, Tarifa y Almería".

Pescadores andaluces contra el gobernador civil.

"Los pescadores andaluces solicitan el cese del Gobierno Civil de Cádiz y del Teniente de la Guardia Civil de Algeciras por las cargas policiales efectuadas sobre los pescadores (...). Unos cuatrocientos pescadores andaluces se encontraban bloqueando, desde primeras horas del pasado día 21, el citado puerto gaditano, impidiendo la entrada de pescado procedente de Marruecos, cuando sufrieron el asalto de la Fuerza Pública (...) continuamente repetían a matarlos

\footnotetext{
${ }^{8}$ Atlántico, 8 de marzo de 1990.
} 
(...) De la totalidad de heridos durante el enfrentamiento, la mayoría de ellos son personas mayores de 55 años." 9

Podríamos continuar transcribiendo más fuentes orales y periodísticas al respecto, pero trataremos de dejar constancia a su vez de la solidaridad y fuerza entusiasta de estas mujeres, quienes denunciaron los apresamientos de los buques que acabaron con el cierre de otro caladero: el de Namibia en $1990^{10}$. Por estos hechos fueron criticadas, pero no cesaron en su protesta, haciéndose presentes en el lugar en que se firmaron los acuerdos, arrojando monedas a los pies de todos los presentes, como un acto simbólico del rechazo al "poder del dinero":

Mujeres de la mar, madres de todas las batallas: "Sus maridos pasan la mayor parte del año en barcos de pesca de altura, sea en aguas de Marruecos, de Sudáfrica, de Malvinas..., colectivo famoso, primero, a raíz de los sucesos que rodearon la firma del convenio para los marineros del banco canario sahariano y, luego por su radical postura frente a aquella plataforma pesquera, a cuyos firmantes tacharon de "peseteros" y arrojaron despectivamente monedas en un espectacular acto del que se hicieron eco la casi totalidad de medios de comunicación (...): Cuando arrojamos las pesetas a aquella plataforma, nos acusaron de haber sido mandadas por Camaño $^{11}$. (...) consideramos que no se contemplaba para nada los problemas de los tripulantes de los barcos que faenan en Namibia. (...) Hubo quien nos acusó de que estábamos en la calle porque no teníamos nada que hacer (...). Cuando estábamos en Marín haciendo guardia para que no hubiese descargas nos llegaron a tratar de putas." 12

Otro de los actos simbólicos de protesta de estas mujeres, referidos por ellas mismas, fue el apoyo al encierro de los tripulantes del pesquero-congelador "Nuevo Alcocero", de la empresa viguesa "Puerta Prado, S.A.", reivindicando los derechos de los marineros en el porcentaje de la pesca, y exigencia de un convenio justo para los trabajadores. La actuación de "Rosa dos Ventos" consistió en manifestarse públicamente y ofrecer comida a los huelguistas. La lucha y la negociación de estas mujeres para la consecución de sus fines, podemos mostrarla en los siguientes testimonios inéditos:

Mujer 1": "Cuando vi las dimensiones del 'Nuevo Alcocero' lo primerito que pensé fue: ¡Cuánto tienen que trabajar esos hombres para llenar esa bodega! Nunca en mi vida vi un barco semejante..."

Mujer 2a: "Creo que fue en el 92 cuando el 'Nuevo Alcocero', un congelador moderno y uno de los más grandes que había en aquellos tiempos, llevaba cincuenta y cinco tripulantes y faenaba en Malvinas, Argentina, cuando en el 92 empezaron con eso de las empresas mixtas..., porque en el 91 cerró Namibia y el problema del cierre del banco de Namibia es que había congeladores aquí en Vigo y al echarlos del caladero de Namibia no tenían donde ir y los mandaron a Argentina. Argentina sí, cogía los congeladores pero sin tripulación, sólo con los titulados. (40\%-60\%), dos de puente..."

Hombre: "El armador metió a los chilenos porque no les pagaba la seguridad social y un sueldo mísero. Ahora mismo, del resto, ni titulados van quedando”.

\footnotetext{
${ }^{9}$ Atlántico, 30 de marzo de 1990.

${ }^{10}$ Las aguas del Atlántico Sur, ricas en recursos, eran tradicionalmente faenadas por los barcos españoles. Namibia al conseguir su independencia el 21 de marzo de 1990 reclama la jurisdicción de sus aguas. Este país del continente africano limita con Sudáfrica, Batswuano, Zambia y Angola. Con una escasa densidad poblacional, el 75\% de sus habitantes viven en zonas rurales, de ahí que no existiera un sector de pesca marítima significativo o de subsistencia. La ZEE de Namibia es una de las más productivas del mundo y su historia pesquera está ligada, por consiguiente, a una intensa trayectoria de pesca masiva incontrolada, realizada por flotas extranjeras. De tal modo que tras la declaración de independencia, la política pesquera de Namibia ha impulsado el desarrollo de dicho sector, con ayudas bilaterales de distintos países, pasando a desempeñar un papel importante en la economía nacional. A partir del reclamo de los mares propios se crean las "sociedades mixtas" donde se produce un intercambio -a distintos niveles- de derechos de acceso a los recursos, capital y bastimentos, así como la aportación de conocimientos, por una larga trayectoria profesional, como es el caso gallego.

${ }^{11}$ Líder sindicalista, varón, afín al Bloque Nacionalista Galego.

${ }^{12}$ Faro de Vigo, 20 de marzo de 1991.
} 
Mujer 2a: "Pero es que cuando fue de 'O Alcocero' fueron cincuenta marineros que se quedaron sin trabajo, sólo de un barco, porque el barco se marchó de Vigo para Argentina con dos titulados de puente: capitán y primer oficial; dos titulados de máquinas y un contramaestre en cubierta. Se perdieron cincuenta puestos de trabajo y luego en otros barcos, por ejemplo los de Pereira, ocurrió lo mismo y con otros tantos congeladores que se fueron a Argentina. Se fueron con cinco titulados o con cuatro titulados y un contramaestre y la marinería se quedó toda sin trabajo. Entonces los que estaban en edad de jubilarse, que a lo mejor no se iban a jubilar, pero ya eso..., hombres con 55, 56 años, ¡me jubilo...! Pero otra cosa que yo destacaría es que cuando fueron los barcos a pescar a Malvinas era un caladero sin explotar y desde Vigo a Malvinas un barco tarda 20-25 días, luego, llegamos allí y en un mes cargaban la bodega"

Hombre: “¡O menos, o antes!”.

Mujer 2a: "Porque era un barco de 1.500 toneladas, en un mes cargaban la bodega y el barco se venía, otros 25 días de ruta ..., que eran más o menos 2 meses y medio, 3 meses". Malvinas".

Hombre: "Siempre se hizo una descarga allí, en un mercante, en 'Port Stander',

Mujer $2^{\mathrm{a}}$ : "No, a o primeiro viñan, venían cada tres meses al principio, llegaban y a lo mejor ganaban en esos tres meses un millón y pico de pesetas, entonces les compensaban. La mayoría del tiempo se lo llevaba la ruta, era un mes sólo de trabajo. Entonces el armador empezó a pensar que a él no le compensaba, ¡y le compensaba! ¡No!, vamos a hacer allá dos descargas y no se puede perder tantos días de ruta para un mes de trabajo. Entonces cambiaron: hacía el barco allí dos descargas y ya venía, entre 25 para allá, 25 para acá y 3 meses de pesca, ya venían de 5 meses, pero llegaban y como a los marineros les descontaban 10 pesetas por cada kilo de pescado que cobraba el mercante por traerlo, resulta que ganaban igual, en vez de 1.200, ganaban 1 millón y medio, pero allá habían trabajado tres meses y era el doble de tiempo, ¿entiendes? Era la avaricia del armador. Luego ya no se conformó con traer el barco a los 5 meses, ya empezaron a dejarlos un año, venía una tripulación en navidades, porque dividían en vacaciones, mandado a una gente para aquí y mandaba de aquí para allá otra, y cuando se acaban las vacaciones de los que venían, esos marchaban y venían los que quedaban a bordo. Trabajo real eran seis meses, a los seis meses cambiaban la tripulación y el barco seguía trabajando continuamente, faenando. Trabajaban 11 meses y descansaban poco más que un mes, más o menos 40 días..., y entonces el barco seguía ya trabajando allí todo el año, hasta que se esquilmó el caladero. Después ya no era rentable, estamos hablando desde el 88 hasta el 91-94". ${ }^{13}$

Las mujeres prorrogaron su activismo en el ámbito público, realizando diligencias ante el Conselleiro de Traballo, quienes propiciaron la negociación de un convenio colectivo para los marineros del banco canario-sahariano. En su acción discursiva mantuvieron que sus prácticas dieron resultados favorables, por su afán en los compromisos adquiridos. Del siguiente modo lo expresaron las informantes:

Mujer 1': "Ahora mismo tenemos hijos mayores pero contar, contar, con las madres. Todas con las madres, yo con mi madre".

Mujer 2a: "Yo cuando empezamos con las movidas tenía una hija de 4 años"

Mujer 1": "Yo a mis hijos los dejaba solos".

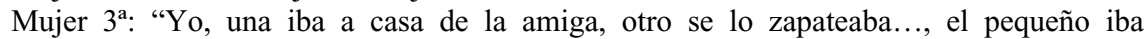
conmigo, o pobre do rapaz mamo seguido aquello, pero bien".

Mujer 2a: "Cuando fue esta lucha por el convenio nos vimos muchas mañanas fuera de casa, porque las manifestaciones en la cooperativa de armadores eran siempre de mañana. Dejábamos los niños en el colegio y nosotros a manifestarnos y veníamos a tiempo de recogerlos. La comida ya por la noche, te organizabas...Y luego en ese tiempo aquí...era la presidenta de la

\footnotetext{
${ }^{13}$ Grupo de debate. Cangas, Pontevedra. Diciembre del 2005.
} 
asociación 'Rosa dos Ventos', ella y yo nos fuimos muchas mañanas a Santiago, a hablar con O Conselleiro de Pesca. Yo dejaba a mi hija en el cole y a veces a pobre de Ana dormía allí, no colegio, hasta que mamá la recogiera, porque yo a mi madre sobre eso no podía decirle, era muy mayor y no podía..."

Mujer 1": "Mi suegra me decía: ¡Ti estás loca o...! ¡Bueno a mi déjeme, déjeme andar...! O sea tampoco era una mujer... que no se metía..."

Mujer 3": "Mi madre sí, mi suegra no lo entendía, mi suegro tampoco".

Mujer 2a: "Bueno mi madre lo único que decía cuando llamaban por teléfono era...jAy Dios mío, inda non veu! Cando llegaba a casa: ¡A ti, a ti cualquier día han de te matar, un día como a o Chincho! (ríen). O Chincho era un señor de Moaña que le pegaron un tiro, en una manifestación hace muchos años. ¡Ti cualquier día...! entonces ella digamos que se quedaba preocupada pero nunca, nunca...,"14

$\mathrm{Y}$ en referencia a las mujeres de Cangas, pertenecientes a "Rosa dos Ventos", la prensa sostuvo:

"Las mujeres de los pescadores de Cangas, que faenan en el banco canario-sahariano, con sus acciones y la presión que han ejercido, han posibilitado que esté a punto de firmarse un convenio en el que se reconoce, entre otras cosas, un salario mínimo interprofesional y vacaciones". ${ }^{15}$

No sólo constatamos su presencia en las manifestaciones y huelgas, sino que trataron de ir más allá. Una Comisión de Mujeres de Pescadores compareció, públicamente en 1990, en la Primera Convocatoria sobre Seguridad y Salvamento Marítimo ante los representantes de las administraciones autonómicas y centrales, de sindicatos y la base del sector. Las activistas leyeron un documento elaborado por ellas y firmado por quince mil personas de distintas zonas costeras, negándose los empresarios a suscribirlo, en el que se denunciaba la inseguridad y las pésimas condiciones laborales de los marineros, revelando que a un "armador le costaba menos la muerte de un trabajador que dotar al buque de los medios necesarios de seguridad y salvamento". La prensa se hizo eco de esta problemática como se muestra en los siguientes fragmentos periodísticos:

López Veiga recibe a mujeres de marineros: "Responsables de la Comisión de Mujeres de Marineros Gallegos entregaron al Conselleiro de Pesca, Enrique López Veiga, el documento sobre Seguridad y Salvamento marítimo (...). El Conselleiro se comprometió a escuchar las sugerencias que le plantee las mujeres en lo sucesivo para realizar entre todos un trabajo eficaz con el fin de conseguir más seguridad para los trabajadores del mar" ${ }^{\prime 16}$

Mujeres de marineros del Banco Canario Sahariano critican a la Administración por no poner más medios para recuperar el Nautilus: "La comisión de mujeres de marineros que faenan en el banco canario-sahariano, de Cangas afirma que nuestros políticos autonómicos lloran ya el gasto de diez millones de pesetas y nuestra indignación llega a límites inimaginables porque no acaba de llegar el buque especializado de Cartagena -o será que entendimos mal y es de Cartagena de Indias-. Nuestros hombres -dicen- no pueden recibir cristiana sepultura y eso a pesar de que los hombres del mar contribuyen a la hacienda pública y parece que la Administración sólo les interesa como fuente de ingreso de divisas" ${ }^{17}$

La Comisión de Mujeres de Marineros pide al embajador de Irán en España que interceda por el capitán Rosales: (...) "Ante el temor de que la guerra del Golfo afecte a su salud física y moral. (...) El capitán Rosales López fue encarcelado en Irán en mayo de 1989 tras

\footnotetext{
${ }^{14}$ Grupo de debate. Cangas, Pontevedra. Diciembre del 2005.

${ }^{15}$ Faro de Vigo, 19 de marzo de 1988.

${ }^{16}$ Galicia, 2 de julio de 1990

${ }^{17}$ La Voz de Galicia, 25 de noviembre de 1989
} 
producirse un derrame de crudo del petrolero de la compañía Nacional de Petróleo de Irán, en el que navegaba como primer oficial al que sucedió una explosión que causó la muerte a quince personas que se encontraban en la inmediaciones." 18

A esta misma cuestión se refieren las fuentes orales inéditas que mostramos a continuación:

Mujer 1a: "Cuando marchamos a Madrid, enero del 89, allí eran sindicalistas de UGT. Allí nos estaban prometiendo el oro y el moro porque yo le dije a... de la manera que me están hablando, mi marido va a cobrar un sueldo normal y luego el porcentaje de pesca. ¡Esto es una mentira! Esto es imposible que me lo de un armador. Porque el armador no te va a dar a ti un sueldo, y después dependiendo de lo que pescaras que te diera un porcentaje porque por las cantidades que ellos daban era... de aquello era jauja y eso no era real. Ellos nos querían hacer comulgar de que era así".

Mujer 2a: "Hombre es que los armadores tienen un barco y de tal manera ese barco viven en malas convivencias, en malas condiciones ese barco, pero él estará tratando de robarle toda la sangre a los marineros para hacer otro barco nuevo. Porque hay armadores que empezaron con un barquito y acabaron con cuatro o cinco, y eso se hace explotando a la gente, no se hace... no invirtiendo en mejoras en el barco, no, invirtiendo en traer más pescado, más pescado y a ser posible reduciendo los gastos".

Mujer $3^{\mathrm{a}}$ : "Aparte, en lo único que pensaban eran en ampliar la bodega, ampliar los tanques de gasoil para que el barco tuviera más autonomía; en vez de estar 60 días que estuviera 100 , pero reduciendo los camarotes, si antes tenían un espacio de 4 metros, a lo mejor, lo dejaba en tres".

Mujer $1^{\mathrm{a}}$ : "En seguridad, sí, hay chalecos para todos los marineros, suele haberlos. Yo creo que sí se ha mejorao".

Mujer $3^{\text {a }}$ : "Hace cuatro años todavía las empresas alquilaban, porque hay también almacenes que se dedican a alquilar y cuando sabían que iban a venir los inspectores los tenían aquella mañana. Cuando salía el inspector, el almacén los venía a recoger otra vez y el barco no llevaba ni salvavidas, ni nada".

Mujer $2^{\mathrm{a}}$ y Hombre:"Eso es culpa del empresario, porque el marinero no lo sabe".

Hombre: "¡Y los mandos, lo saben, ellos lo saben!"

Su singladura continuó con la proyección de un trabajo de sensibilización, que dio como resultado la adquisición de nuevos medios de salvamento para el sector pesquero gallego, en concreto: dos remolcadores de altura, dos helicópteros y cuatro lanchas rápidas. Éstas sostienen como dichas experiencias fueron decisivas para evolucionar de un colectivo espontáneo a una asociación formal, disponiendo de unos recursos económicos para su impulso, de tal manera que el 5 de Febrero de 1991 nació la Asociación de Mujeres de Pescadores de las Rías Bajas de Galicia, "Rosa dos Ventos", con independencia de la política partidista, de sindicatos y de organismos públicos. En sus bases estatutarias apreciamos los valores de "solidaridad, justicia, dignidad y fuerza liberadora del mundo marítimo" incidiendo en aspectos como el desarrollo y la formación para los marineros, como también la concienciación e implicación de los hombres en sus acciones cotidianas. Dicha asociación denuncia la marginalidad a la que están expuestos los trabajadores del mar y sus familias, planteándose entre sus objetivos, fomentar la promoción de las mujeres de pescadores a través de encuentros o jornadas de debate, tanto a nivel local y nacional como internacional. Todas las actividades de las que venimos hablando están reseñadas en Boga, "Revista Internacional de Mujeres de Pescadores", creada en 1989.

\footnotetext{
${ }^{18}$ La Voz de Galicia, 27 de enero de 1991.

${ }^{19}$ Grupo de debate. Cangas, Pontevedra. Diciembre del 2005.
} 


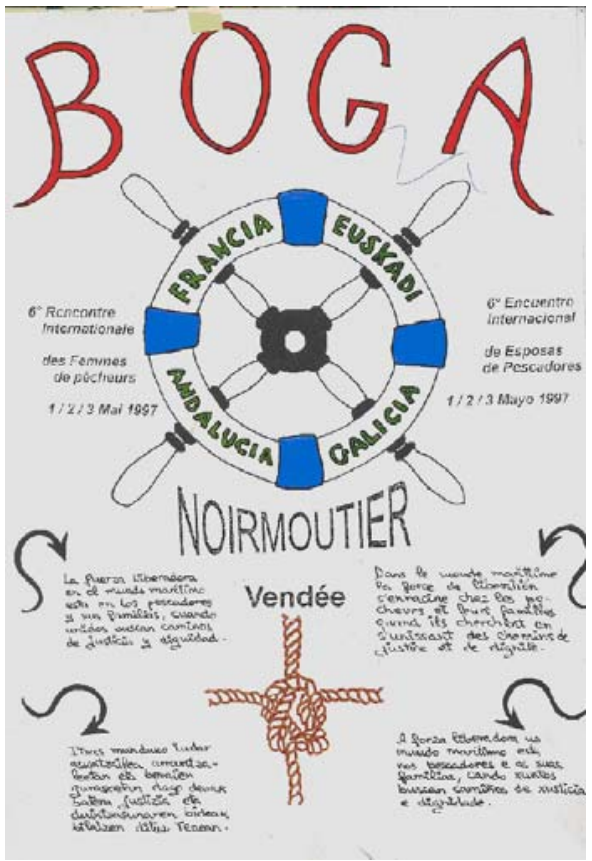

Autoelaboración de "Boga"

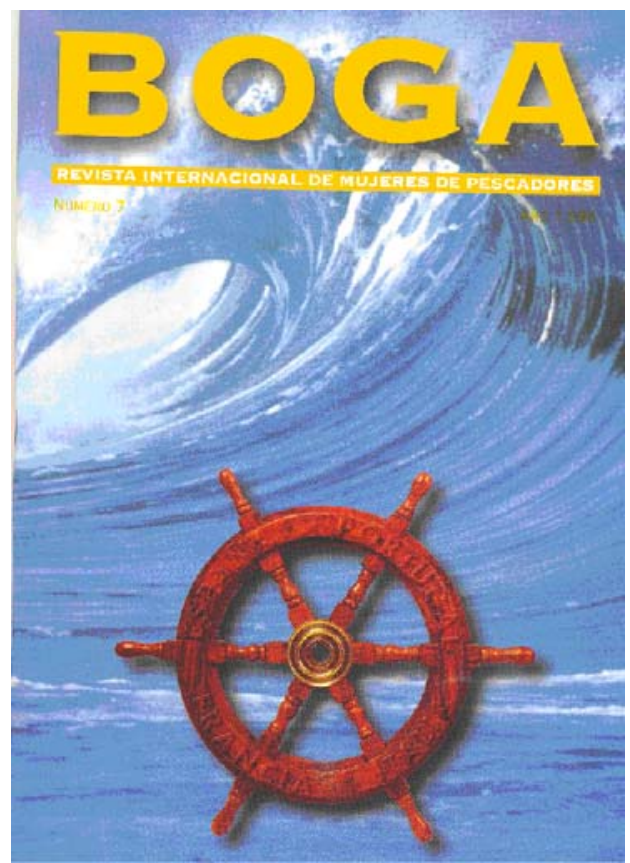

Publicación financiada de "Boga"

Este colectivo de mujeres se hizo oír en los distintos encuentros sobre temas marítimos, es el caso de su representación en convocatorias sobre cotizaciones y jubilación anticipada en el año 1992, en los años 1993 y 1994 presentaron ponencias sobre seguridad en sendos congresos celebrados en Luxemburgo, participando en el año 1996 en diferentes congresos, donde abordaron temas sobre las repercusiones sociales de las empresas mixtas en la vida laboral de los pescadores y sus familias. También en el año 1997 asistieron al encuentro internacional de mujeres de pescadores, celebrado en Noirmoutier (Francia), con la propuesta de reivindicar en el Parlamento europeo (Bruselas) los derechos universales de las familias vinculadas a la pesca, realizando gestiones con representantes del Parlamento europeo, y con la asociación francesa "Uhaina" asistieron a una comparecencia en el Parlamento de Estrasburgo para explicar la situación de las familias, en la que leyeron un documento conjunto centrado en la premisa: "El equilibrio de la familia del marino depende de una mejora de las condiciones de la vida en la mar y en tierra", con la siguiente propuesta: "No a las ayudas europeas a empresas y Estados miembros sin garantía social". De este modo, mujeres de distintas nacionalidades se comprometían a "luchar unidas", por lo que había nacido cierto internacionalismo espontáneo. La prensa se hizo eco de sus reivindicaciones en los siguientes términos:

Mujeres de pescadores piden a la UE que no conceda ayudas si no hay garantías sociales: "Los colectivos de mujeres de pescadores de España, Francia, Portugal e Italia pidieron en Estrasburgo que la UE no conceda ayudas para las empresas del sector y los Estados miembros si no existen garantías de mejorar las condiciones sociales de los marineros". ${ }^{20}$

"Queremos luchar unidas para conseguir para nuestros hijos lo que nosotros no hemos tenido y que las condiciones del trabajo en la mar mejoren" 21

\footnotetext{
${ }^{20}$ Faro de Vigo, 15 de marzo de 1998.

${ }^{21}$ Faro de Vigo, 19 de marzo de 1998.
} 
Por su parte, las mujeres francesas declararon respecto a sus colegas españolas:

"Las españolas cuentan con menos recursos, pero son más valientes y combativas. Esperamos que estos encuentros sigan adelante para conseguir solidaridad y logros que redunden en beneficio de las familias"22.

Las propuestas de "Rosa dos Ventos" se han orientado también a la defensa medioambiental, como se aprecia en la siguiente nota de prensa:

"Las mujeres de Rosa dos Ventos se movilizan contra las extracciones de arena en la Costa de A Vela" 23 .

Asimismo la referida asociación también apoyó la investigación en temas de desarrollo tecnológico, al servicio de la seguridad y el salvamento marítimo, como se desprende de la siguiente noticia:

Rosa dos Ventos apoya las nuevas tecnologías para evitar naufragios: (...) "La asociación de mujeres Rosa dos Ventos expresó ayer su pésame a los familiares del "Siempre Cansina" (...). La agrupación de mujeres de pescadores quiso valorar las declaraciones realizadas por el ingeniero naval Primitivo González. Este técnico aseguró que barcos del tipo del "Siempre Cansina" deberían ser "insumergibles" al tiempo que manifestó que el diseño se basaría en grandes flotadores en el interior del casco con capacidad suficiente para mantenerlo a flote ante estos accidentes. Por este motivo, las integrantes del colectivo no dudan en expresar su indignación ante el hecho de que algunas empresas hayan intentado desarrollar este sistema de seguridad pero sin haber tenido aceptación debido a su coste. "Rosa dos Ventos" concluye que la vida de un hombre no tiene precio, por lo que apoya la investigación para mejorar las condiciones de trabajo en el mar". ${ }^{24}$

Ahora bien, nos podemos preguntar: ¿cómo continúa el relato de vida de "Rosa dos Ventos", su historia de lucha por los derechos humanos, y su internacionalismo de los hombres y las mujeres del mar? Consideramos que por un camino embaucador que responde a una "trampa" propuesta por una convocatoria de la Comisión Europea (98/C 58/09), para la concesión de ayudas a acciones de información y experiencias a favor de la familia y la infancia. Dicha iniciativa, "Medidas a favor de la familia y los niños", se publicó en el Diario Oficial de la Comunidad Europea con fecha del 24 de Febrero del año 1998. De este modo se puso en marcha un proyecto transnacional denominado FEMMES (Familias Europeas de Marinos) con la participación de asociaciones de mujeres de Francia, Alemania, Bélgica, Finlandia y España, bajo el objetivo de "la conciliación del trabajo con la vida familiar", y con el patrocinio del Parlamento Europeo y la Comisión de Empleo y Asuntos Sociales. Los inicios de este propósito contaron con el experimentado y acostumbrado "voluntarismo" de dichas mujeres, inaugurándose en octubre de 1999 el Proyecto FEMMES con un Congreso Nacional en Vigo, donde se constató que la calidad de vida de las familias de marinos españoles se encuentran entre las últimas a nivel europeo. Y el camino ya estaba trazado.

Las siguientes fuentes periodísticas continúan mostrando la actuación de esta asociación, a favor de una humanización del trabajo realizado por los hombres en la mar, más institucionalizada que espontánea:

Rosa dos Ventos pide que los fondos IFOP vayan unidos a garantías sociales para los marineros: (...) "El objetivo era exponer las condiciones en las que trabajan los marineros españoles, que son las peores de los países más desarrollados de Europa, así como el excesivo tiempo que pasan en el mar, que en las mareas de cuatro meses realizan un trabajo como si permaneciesen seis meses faenando. Este exceso de horas repercute también en las condiciones de seguridad del tripulante (....) Por esta razón solicitaron al ministro que busquen las fórmulas para que los marineros trabajen cuatro meses y descansen dos. Las mujeres de los marineros españoles

${ }^{22}$ Faro de Vigo, 19 de marzo de 1998

${ }^{23}$ Faro de Vigo, 22 de febrero de 1993.

${ }^{24}$ Faro de Vigo, 25 de febrero del 2005 
pidieron que a los armadores que se les conceden ayudas del Instrumento Financiero de orientación de la Pesca (IFOP) para la renovación se les exijan garantías sociales para los tripulantes. De esta forma se podría pagar con fondos IFOP los meses de vacaciones (...) De los 150.426 marineros europeos del sector pesquero y mercante, 97.874 son españoles y están en el vagón de cola en lo que respecta a calidad de vida, ya que en ninguno de los países más desarrollados de Europa permanecen nueve o diez meses en el mar. La situación se agrava en el caso de las empresas mixtas" 25 .

En noviembre del año 2002 se promovió en Vigo el Congreso Nacional acerca de "La protección laboral y social de la familia marinera", y en el año 2003 una Conferencia Europea sobre "El papel de la mujer en la pesca", celebrada en Bruselas congregando a 200 mujeres de 16 países invitados por la Comisión Europea, entre ellas se encontraban representantes de la asociación "Rosa dos Ventos". En el año 2004 se celebró en Santiago de Compostela un fatuo Simposio sobre "La mujer en la pesca, la acuicultura y el marisqueo en el contexto comunitario", donde predominaron las voces de los "expertos".

Para concluir traemos a colación los siguientes testimonios que exponen el estado actual de dicha asociación:

Hombre: "Va muy bien, viento en popa" (sonríe...)

Mujer 1": "Bueno, ahora estamos en una cosa que se llama FEMMES, piensan en federarse. El proyecto ha sido muy bien acogido en Bruselas, donde está muy bien reconocida la asociación".

Hombre:" Está muy politizada esta asociación... eso se termina".

Mujer 2a: "Desde que se formó, hasta ahora, el cambio fue de $360^{\circ}$ en contra. Se lograrían muchas cosas, yo no lo discuto, pero la unión, la energía de decir si hay que llamarle a éste cuatro cosas y se le dicen a la cara... ahora no se le dicen, ahora se callan porque hay subvenciones. El problema de esta asociación fue meter las subvenciones dentro".

Hombre: "Ahora es asociación de cuatro, las que están mandando".

Mujer 3a: "¡Eso es mentira eh!"

Hombre:" Cala a boca, sí hombre sí".

Mujer 1": "La mayoría de las socias estamos aquí, en Cangas, pero ya ha bajado mucho el número de socias, por unas cosas u otras la gente se fue desencantando y dando de baja. Yo creo que una de las cosas fue lo que estuvimos hablando, de que por el cierre del caladero de Canarias se han reconvertido unos, otros se han jubilado que a lo mejor había marineros ahí que pensaban trabajar algunos años más, pero con el cierre del caladero cogieron la jubilación y otros se han ido a otros caladeros. Mi marido, por ejemplo, se fue a otro caladero, porque sus hijos aún estaban estudiando. Ahora se jubiló el año pasado, porque en Namibia empezó a ponerse la cosa bastante complicadilla también, como que quieren poner más gente de allí, más namibios y menos de aquí. A mi lo que me llamó la atención es que el viernes precisamente tuvimos la asamblea general, y de 137 socias ahora mismo somos 53, entonces... y en la reunión habría unas 22 . La bajada pudo ser por muchas cosas, lo podemos resumir".

Mujer 2a: "Vamos a ver, yo estuve en la directiva, tu estuviste en la directiva, hubo otras antes y después de mí".

Mujer 1": "Yo estuve de portavoz de la asociación durante... bueno desde el 88 nos formamos como comisión de mujeres, luego se hizo la asociación en el 90 y seguí de portavoz, y en el 95, pues se politizaron un poquito las cosas y yo dejé de ser portavoz. Para mí lo politizaron tres hombres, no mujeres, dos personas de la asociación. Si es una asociación "de mulleres de marineros", entonces si yo soy la portavoz y me llama la mujer de un marinero que es coordinadora y dice la coordinadora: 'hay que sacar esta nota de prensa, tacata...porque fulano di

${ }^{25}$ Faro de Vigo, 27 de julio del 2000. 
que hay que sacar esta nota de prensa'. A mí este señor no es nadie para darme orden y decir como tengo que escribir una nota de prensa". ${ }^{26}$

- ¿La asociación está constituida por mujeres o mujeres y hombres?

Todas: "Mujeres, sólo mujeres".

Mujer 1:"'Entonces por ahí ya empezamos mal...fulanita dejó la presidencia, yo dejé el cargo y después empezaron a venir...después resulta que la persona que era coordinadora (a lo mejor ellas no están de acuerdo con lo que yo voy a decir y no voy a empezar en rollos de crítica, porque no soy quién para juzgar a nadie ), pero hubo la persona, la vocal coordinadora, que luego ella hacía de coordinadora, de portavoz, de presidenta, de vicepresidenta..."

Mujer 3": "Claro".

Mujer 2a: "Ella lo hacía de todo".

- ¿Mujeres de?

Mujer 2a: "Mujer de patrón".

Mujer 3a: "Bueno, tú lo sabes el jaleo que hubo el año pasado en la asamblea general porque hizo una pregunta que no la tenía que hacer, un jaleo... Yo este año ya no fui porque iba a hacer la misma pregunta... iporque no me la contestaron!".

Mujer $1^{\text {a: }}$ "A ella la estaban moviendo, ella es títere delante de aquellas dos personas".

- ¿Y lo de Bruselas, veis positivo estar conectadas en otras instancias y con otras personas?, ¿este trabajo internacional supone un beneficio para vuestras demandas?, ¿es idóneo o no, estar dentro de este mundo globalizado?

Mujer 2a: "Yo pienso que esta asociación perdió. A nosotros Bruselas es que estamos en Europa, y a nosotros como Estado español, Bruselas nos queda muy lejos. La asociación a nivel asociación, Bruselas nos queda muy lejos, y ahora la asociación está mirando mas para fuera que para dentro" 27 .

En consecuencia podemos concluir que la práctica gubernamental ocupa un lugar preponderante en su relación con la sociedad civil, jugando un papel esencial en la orientación de las mujeres y en el desmantelamiento de sus acciones, tal como han referido con la "recapitulación" de su historia, en el marco de un asociacionismo que se expresa desde los confines del comunitarismo y del internacionalismo, creado a finales de los años ochenta y principios de los noventa, para entrar posteriormente en confrontación directa contra las "tecnologías de gobierno"

Desde el recorrido del colectivo femenino, narrado por su propia intrahistoria de independencia y autonomía alcanzada, hasta su inclusión en las ONGs, sólo hay un paso para la disuasión de la acción, e inclusive la manipulación y el control social. Asimismo la defensa por la dignidad y los derechos humanos de unas poblaciones estigmatizadas se manifestó en el contenido del texto, revelando el verdadero alcance de esta lucha feminista:

"Después de las experiencias vividas a partir de nuestro compromiso en la lucha por el convenio colectivo del banco canario-sahariano, de la flota de cefalópodos, por conseguir su primer convenio colectivo. Ante la intransigencia de la patronal, los marineros chocaron también con los sindicatos mayoritarios que no apoyaron este convenio, UGT Y CCOO (...). Nosotros pensamos que esta defensa se refiere a los trabajadores de tierra, porque a los trabajadores del mar

\footnotetext{
${ }^{26}$ Grupo de debate. Cangas, Pontevedra. Diciembre del 2005.

${ }^{27}$ Grupo de debate. Cangas, Pontevedra. Diciembre del 2005.
} 
estos señores -igual que otros responsables de pesca- los marginan y contribuyen a que su vida siga siendo una esclavitud (...). Si antes con la dictadura los marineros eran tratados como ciudadanos de segunda categoría, ahora en la democracia los tratan como tercermundista (...), la única respuesta de los responsables es el de mandar 'cargar' a la policía (...). No menos reprochable fue la actitud de nuestros gobernantes con respecto a los accidentes marítimos (...). Octubre del 89 para acordarnos del 'Nautilus', o mejor, de sus cinco tripulantes que siguen en el fondo del mar (...). Todos sabemos que los métodos utilizados fueron tercermundistas, ya que cuando estaban localizados no pudieron rescatarse los cadáveres. Si dolorosos fue este suceso, de sangrante podemos calificar lo que aconteció el 17 de diciembre. Un barco, el 'Velasco II', lanza un SOS durante horas pidiendo ayuda, junto a él otros dos barcos piden ayuda para estos once compañeros, pero los responsables en salvamento marítimo no se ponen de acuerdo para salir a socorrerles (...). A raíz de esta tragedia no oímos tampoco la voz defensora de los derechos humanos de los sindicatos mayoritarios (...). Vivimos estos días las protestas que llevaron a cabo los pescadores andaluces, apoyados también por pescadores gallegos que faenan en el mismo caladero. (....). Son débiles a causa de la lejanía"28

Una vez expuesta, a través de las fuentes orales y periodísticas, la naturaleza de las relaciones entre Estado y género, podemos reflexionar sobre el ámbito privado al que las mujeres están históricamente confinadas, pues dentro de tan obviado territorio hemos evidenciado como las políticas dominantes inciden en aumentar las tareas reproductoras, ya no sólo a modo de "terapias ocupacionales" transmitiendo similares esquemas, que están en manos de las mismas, al reducir el salario social y convertir en más precarias aún las tareas realizadas por las mismas. Por tanto nos encontramos con un antiguo presupuesto, esto es, que en determinadas condiciones las mujeres son quienes compensan, con sus trabajos familiares, las pérdidas generadas por el repliegue social y económico del Estado, transfiriendo, por consiguiente, una determinada economía sumergida a determinados sectores socio-sexuales. En definitiva, estimamos que el ámbito estatal materializa, reproduciendo bajo renovados mecanismos, la incisiva disociación de las esferas públicas y privadas, como supuesto resultado de las diferencias naturalizadas entre hombres y mujeres. Una división perpetuada y consolidada por el desarrollo de políticas que fortalecen el cumplimiento de roles acordes al género, si bien la praxis de determinados períodos históricos y contextos culturales muestra que dicha separación dicotómica se pone en cuestionamiento, cuando las políticas sociales de los países asumen tareas reproductivas, bajo una sutil conexión con la esfera privada.

Para la observación y el análisis sobre el poder ejercido desde el Estado, tomamos como referencia algunas de las herramientas analíticas orientadas a entender los mecanismos políticos de persuasión y orientación en relación a la población. Sería Michel Foucault quien distinguió con el término de "biopolítica" el modo en que el Estado, a partir del siglo XVIII, y en especial desde el siglo XIX con el liberalismo, instauró el ejercicio del poder mediante el uso de una "tecnología" dirigida a la anatomía política del cuerpo humano ${ }^{29}$. Los asuntos de la sociedad civil se convierten en una cuestión de Estado, intentando racionalizar una serie de cuestiones en torno a los sujetos sociales, entendiendo como "poblaciones", todo lo relativo a la natalidad, la salud, la higiene, etc., dentro de una propia "tecnología de gobierno" 30 "Dispositivo de subjetivización" que mediante la práctica discursiva y la acción de la población representada en nuestro texto, hemos podido comprobar el modo de victimizar y/o estigmatizar la identidad de los sujetos a favor de un "orden social" legitimado.

\footnotetext{
${ }^{28}$ Colaboración femenina publicada en Revista AETINAPE, Asociación Española de Titulados Náutico-Pesquera, $\mathrm{n}^{\circ} 29$, Coruña, abril de 1990, pp.31-2.

${ }^{29}$ FOUCAULT, M., "Del poder de soberanía al poder sobre la vida", en Genealogía del racismo, De la guerra de razas al racismo de Estado, La Piqueta, Madrid, 1992, pp.247-273, pp. 250-254. Sobre los conceptos de "Anatomopolítica" "Biopoder" y "Biopolítica", véase FOUCAULT, M.: Historia de la sexualidad I. La Voluntad de saber, Siglo XXI, México 1976; Vigilar y Castigar. El nacimiento de la prisión, Siglo XXI, México, 1975.

${ }^{30}$ FOUCAULT, M.:"La gubernamentalidad", en FOUCAULT, M.: Espacios de Poder, La Piqueta, Madrid, 1981, pp. 9-26.
} 